\title{
||||||||||||||||||||||||||||||||||||||||||||||||||||||||||||||||||.
}

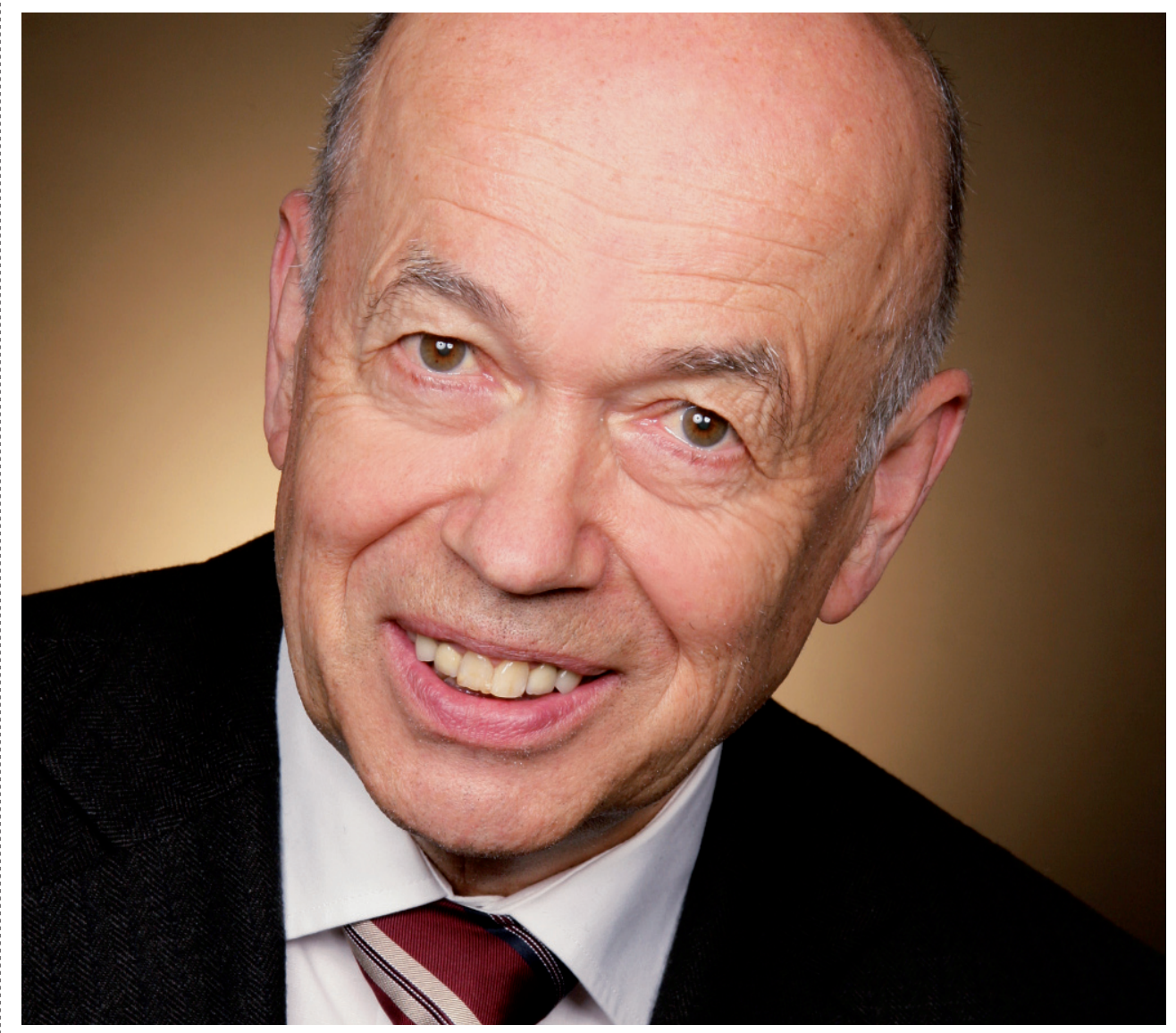

PROF. DR.-ING. ULRICH SEIFFERT

Technische Universität Braunschweig

\section{VIELFALT IM ANTRIEBSSTRANG}

Wer gehofft hat, dass sich für die Fahrzeughersteller im Jahr 2011 durch eine Fokussierung auf bestimmte Antriebskonzepte eine Erleichterung in der Entwicklungs-, Produktions- und in der Verkaufsorganisation ergeben könnte, muss erkennen, dass die Komplexität auf dem Antriebssektor für Straßenfahrzeuge eher noch zugenommen hat. Dies gilt umso mehr, da im weltweiten Automobilmarkt große regionale Unterschiede vorhanden sind. So wird neben den herkömmlichen Otto- und Dieselfahrzeugen eine wachsende Zahl von Alternativen angeboten. Sie reichen von mit Gas angetriebenen Fahrzeugen (CNG und LPG) über Hybridantriebe, Plug-in-Hybride als Range Extender bis hin zu reinen Elektrofahrzeugen. Interessanterweise haben sich auch die Forschungs- und Vorentwicklungsaktivitäten für Brennstoffzellenfahrzeuge wieder erhöht. Daneben müssen die Verbrennungsmotoren ebenfalls in Richtung Kohlendioxidminimierung getrimmt werden. Die Gründe für die eher noch wachsende Vielfalt sind vielschichtig. Sie reichen von der zur Verfügung gestellten Antriebsenergie und deren Verteilung bis zur Optimierung des klassischen Verbrennungsmotors mit Downsizing und Aufla- dung. Auch das Getriebe gewinnt an Bedeutung, da sich dort die Anzahl der Varianten ebenfalls erhöht. Die Spannweite umfasst Getriebe mit wenigen Gängen bei reinen Elektrofahrzeugen bis zu Automatikgetrieben mit einer hohen Anzahl von Gängen. Fahrzeughersteller, die nur einseitig auf spezielle Antriebsvarianten setzen, werden im weltweiten Markt bitter bestraft. Auch Regierungserklärungen verkaufen nur selten Fahrzeuge mit dem notwendigen Gewinn. Umso mehr benötigen wir daher eine europäische Energiepolitik, die alle erwähnten Varianten mit einbezieht. Speziell für die Elektrotraktion ist $\mathrm{CO}_{2}$-freier Strom notwendig und die Verteilungs- sowie die Batterieladesysteme müssen installiert werden. Ein wesentlicher Beitrag zur $\mathrm{CO}_{2}^{-}$ Reduzierung könnte die Wiederverwertung von $\mathrm{CO}_{2}$ sein, bei der durch das ,eingefangene $\mathrm{CO}_{2}$ “ aus Kohlekraftwerken mithilfe von $\mathrm{CO}_{2}$-freiem Überschussstrom eine entsprechende gasförmige oder flüssige Kraftstoffenergie gewonnen wird. Auch die Brennstoffzelle ist von einer entsprechenden Wasserstofferzeugung und Verteilungsinfrastruktur abhängig. Für eine intensive Arbeit für die Ingenieure auf obigen Gebieten ist gesorgt. 